\title{
SWOT Analysis for Shanghai's Serviced Apartment
}

\author{
Shen Hong ${ }^{1, a}$, and Jiang Zhenzhen ${ }^{2}$ \\ ${ }^{1,2}$ Shanghai University of Finance and Economics \\ Department of Public economic and Administration, Shanghai, China \\ a shcdshenhong@sina.com
}

Keywords: Serviced apartment, SWOT analysis, Shanghai business area

\begin{abstract}
With the acceleration of building Shanghai as an international financial center, a large number of small and medium-sized enterprises and foreign firms are stepping up to seize the market. Business and tourism floating population keep increasing. Data of the 6th Population Census showed that Shanghai's resident population has reached 23019148, and population coming from other provinces but now living in Shanghai for more than half a year has reached 8977000, which accounting for the city's resident population of 39\%. ${ }^{7}$ High percentage of non-native population led to housing consumption problems. The traditional hotel seems too expensive for people who want to settle down for a long time. The serviced apartment which appeared in the 1990s in China, has won a large number of small and medium-sized enterprises and expatriate managers' favor because of the hotel-style services, apartment-style management and relatively cheap prices. And it is still developing very fast. This article is focus on analyzing Shanghai serviced apartment by SWOT, so as to provide suggestions for consumers.
\end{abstract}

\section{Problem Posing}

Serviced apartment is a residential unit which is mainly for rent or investment, with the subject of standardization management and people-oriented service, integrated residence, hotel and club in one building. It is a special property type with both hotel-typed service and apartment-typed administration. Besides, as a comprehensive property type, serviced apartment also reflects features of office building of today's information era - possess good communication conditions, customized provide secretarial service, information, translation and other business services. ${ }^{1}$

Serviced apartment concept originated from Europe, which was developed for tourists' temporary rest in tourism area. Even if it was for a short break, it provided unified visiting service like hotel, and also worked as personal temporary homes. All of these formed the embryo of serviced apartment. Not long after, such property became more and more and its service got more and more considerate and popular.

The serviced apartment of China first appeared in Shenzhen in 1980s, and arose in Shanghai and other big cities since it fit with the situation of rapid increase of floating population ratio and fast development speed in urban areas. This article carries on SWOT analysis for Shanghai serviced apartment and so as to provide certain reference for consumers.

\section{Strength analysis for Shanghai serviced apartment}

\section{Advantageous Geographical Location and Convenient Transportation.}

Serviced apartments are mainly located in districts with rich business atmosphere. Table 1 list the location of serviced apartment in Shanghai and most of which are in three commercial centers.

Full house structures and suitable for all kinds of householder.

Serviced apartments are mainly small spaced, with about 50 square meters per unit, and can be commonly found as one-bedroom and two-bedroom. Table 1 demonstrates some representative ones 
in all districts of Shanghai, space of which ranges from $38 \mathrm{~m} 2$ to $158 \mathrm{~m}^{2}$, which can fit different levels of requirements.

\section{High Performance Price Ratio}

Monthly rent per square meter is relatively cheaper than general hotels, with the minimum 48 yuan/ $\mathrm{m}^{2}$ and maximum 944 yuan/ $\mathrm{m}^{2}$. Table 1 list the monthly rent per $\mathrm{m}^{2}$ ranges from 116 to 994, which has absolute advantage relative to general hotels. Serviced apartments are separate flat, they provide more convenient living and require lower cost (the rent of which equals to $40 \%$ of that of similar hotels), with almost the same level of hardware and software ancillary facilities with hotels. Picture 1 also shows that, serviced apartments in central zone like Luwan District have the least price advantage; while Songjiang has obvious advantage.

Table 1 Part of Serviced Apartment List

\begin{tabular}{|c|c|c|c|c|}
\hline Estate & Address & $\begin{array}{c}\text { Area } \\
\left(\mathrm{m}^{2}\right)\end{array}$ & $\begin{array}{c}\text { Total unit } \\
\text { number }\end{array}$ & $\begin{array}{c}\text { Monthly average } \\
\text { rent }(\text { yuan/m² }\end{array}$ \\
\hline New Space & No.99, Huichuan road, Changning District(Zhongshan Park area ) & $42 \sim 68$ & 100 & $171 \sim 217$ \\
\hline $\begin{array}{c}\text { Bailing } \\
\text { Wanyuan }\end{array}$ & $\begin{array}{c}\text { No.599, Pudong Avenue, } \\
\text { Pudong (Lujiazui business area) }\end{array}$ & $56 \sim 80$ & 337 & $116 \sim 160$ \\
\hline $\begin{array}{c}\text { Greenland } \\
\text { Hotel }\end{array}$ & No.193, Xiehe Road. Changning District(Hongqiao business area) & $45 \sim 56$ & 30 & $266 \sim 357$ \\
\hline $\begin{array}{c}\text { Zhongxin 5 } \\
\text { cows' city }\end{array}$ & No.1089, Pudong Avenue,Pudong (Lujiazui business area) & $42 \sim 65$ & 130 & $261 \sim 338$ \\
\hline 88xintiandi & No,380, South Huangpi Road, Huangpu Distraict(Huaihai Road) & $42 \sim 56$ & 53 & $357 \sim 380$ \\
\hline Dijing Park & No.999, Zhaojiabang Road, Xuhui Distraict(Xujiahui) & $57 \sim 158$ & 105 & $221 \sim 298$ \\
\hline $\begin{array}{c}\text { Xileting } \\
\text { Jinqiao }\end{array}$ & No.55, West Beijing Road, Huangpu District(People's Square) & $27 \sim 62$ & 260 & $459 \sim 944$ \\
\hline Ascott & No.282, Middle Huaihai Road, Huangpu District(Huanhai Road) & $59 \sim 155$ & 278 & $556 \sim 760$ \\
\hline $\begin{array}{c}\text { Huishengtin } \\
\text { International }\end{array}$ & No.98, Shouning Road, Huangpu District(Huanhai Road) & $63 \sim 117$ & 276 & $416 \sim 509$ \\
\hline Xihua & No.1, West Huaihai Road, Xuhui District(Xujiahui) & $16 \sim 36$ & 168 & $675 \sim 800$ \\
\hline Hengyuan & No.728, Hongjing Road, Minhang District(Hongqiao business \\
\hline
\end{tabular}

(Data Sources: Network data cleansing)

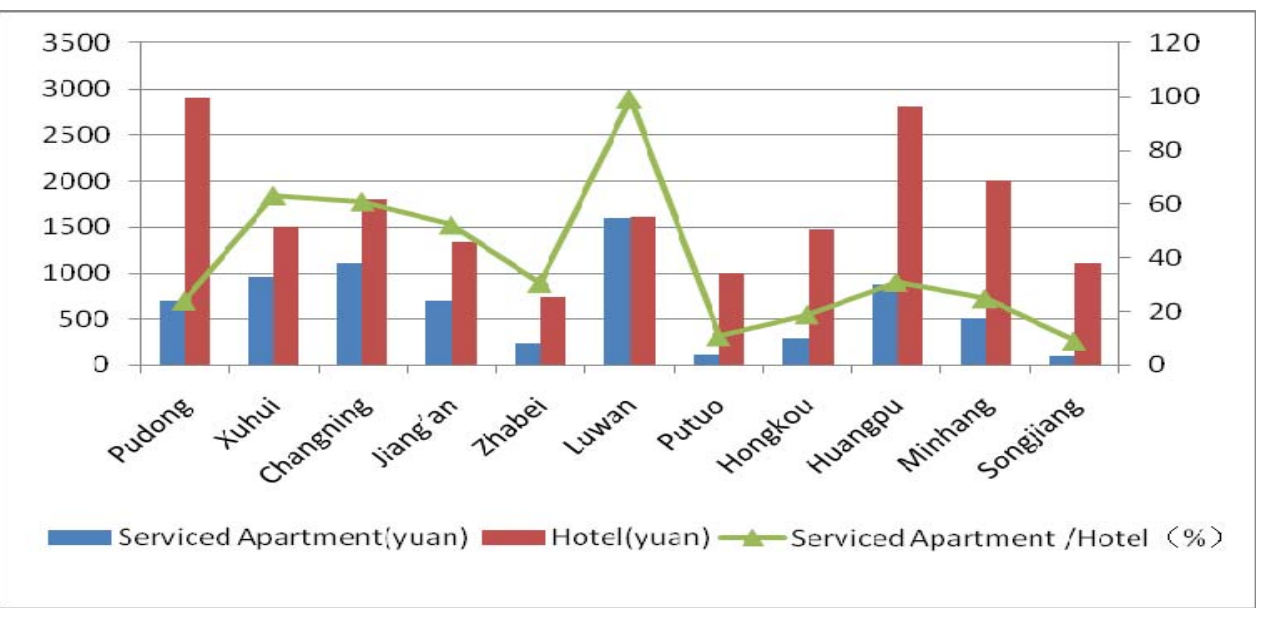

Picture 1 Price Comparison between luxury Serviced Apartment and Same Level Hotels in Shanghai

Table 2 Evaluation List for Part of Serviced Apartment

\begin{tabular}{|c|c|c|c|c|c|c|c|c|c|c|c|c|}
\hline Estate & $\begin{array}{c}\text { To- } \\
\text { tal }\end{array}$ & $\begin{array}{c}\text { Faci } \\
\text {-lity }\end{array}$ & Price & $\begin{array}{c}\text { Loca- } \\
\text { tion }\end{array}$ & $\begin{array}{c}\text { Restau- } \\
\text { rant }\end{array}$ & $\begin{array}{c}\text { Trans } \\
\text { port }\end{array}$ & $\begin{array}{c}\text { Ser- } \\
\text { vice }\end{array}$ & $\begin{array}{c}\text { Repu- } \\
\text { tation }\end{array}$ & $\begin{array}{c}\text { 2-star } \\
\text { Rank }\end{array}$ & $\begin{array}{c}\text { 3-star } \\
\text { Rank }\end{array}$ & $\begin{array}{c}\text { 4-star } \\
\text { Rank }\end{array}$ & $\begin{array}{c}5 \text {-star } \\
\text { Rank }\end{array}$ \\
\hline New Space & 4.3 & 4.0 & 4.1 & 4.4 & 4.1 & 4.7 & 4.4 & 126 & 34 & - & - & - \\
\hline $\begin{array}{c}\text { Bailing } \\
\text { Wanyuan }\end{array}$ & 3.8 & 3.8 & 4.0 & 3.7 & - & 3.9 & 3.6 & 1215 & 339 & - & - & - \\
\hline Greenland Hotel & 3.9 & 4.2 & - & 3.5 & - & 3.7 & 4.0 & 866 & 203 & - & - & - \\
\hline $\begin{array}{c}\text { Zhongxin 5 } \\
\text { cows' city }\end{array}$ & 3.9 & 3.6 & 4.6 & 4.3 & 4.0 & 4.1 & 3.0 & 866 & - & 107 & - & - \\
\hline 88Xintiandi & 4.1 & 4.3 & 3.7 & 4.3 & 3.6 & 4.5 & 4.3 & 456 & - & - & 94 & - \\
\hline Dijing Park & 4.3 & 4.0 & 4.3 & 4.6 & 4.0 & 4.8 & 4.1 & 126 & - & - & 20 & - \\
\hline
\end{tabular}




\begin{tabular}{|c|c|c|c|c|c|c|c|c|c|c|c|c|}
\hline Xileting Jinqiao & 4.3 & 4.1 & 4.3 & 4.7 & 3.9 & 4.7 & 4.2 & 126 & - & - & 20 & - \\
\hline Ascott & 4.1 & 3.8 & 3.2 & 4.7 & 4.1 & 4.7 & 3.8 & 456 & - & - & - & 80 \\
\hline $\begin{array}{c}\text { Huishengtin } \\
\text { International }\end{array}$ & 4.0 & 4.2 & - & 4.0 & 4.0 & 3.9 & 3.9 & 665 & - & - & 134 & - \\
\hline Xihua & 3.9 & 3.8 & 3.9 & 4.0 & 3.9 & 4.0 & - & 866 & - & - & 165 & - \\
\hline Hengyuan & 4.1 & 4.3 & 4.2 & 4.0 & 4.1 & 4.1 & 3.6 & 456 & - & - & 94 & - \\
\hline Average & 4.1 & 4.0 & 4.0 & 4.2 & 4.0 & 4.3 & 3.9 & - & - & - & - & - \\
\hline
\end{tabular}

(Data source: Sorting by http://www.qunar.com. Full Score is 5.0.)

\section{Weakness Analysis for Shanghai Serviced Apartment}

\section{Service level should be further enhanced}

From the results of five factors for 11 serviced apartment evaluated by Qunar.com in Table 2, we can see that the service index got the lowest score and the average was only 3.9.

Both hardware and software facilities need to be improved.

From the results of five factors for 11 serviced apartment evaluated by Qunar.com in Table 2, facility index was the second-lowest, with average score as 4.0 , which was below the grand average 4.1. Hence it requires more improvements.

\section{Opportunity Analysis for Shanghai Serviced Apartment}

\section{Rise of commercial tourists}

Shanghai gradually develops into an international financial center. Different kinds of business negotiations, international exhibitions, international conferences etc are seen everyday. Big increase is found in the population of foreign official travelers, business guests and tourists and the time of stay is also longer. Figures in Picture 2 shows a steady 2-digit increase in 2010 compared with 2009, average $30.79 \%$ for the whole year. This high rate is caused mostly by the opening of World Expo and it keeps this rate in 2011. The first 8 months of 2012 has also seen a steady growing trend with a single digit increase compared with the corresponding period in 2011. The average entry amount has grown steadily from 17.23 thousand per day to 23.318 thousand in 2010, and 22.3967 thousand in 2011 to 25.1943 thousand in 2012.

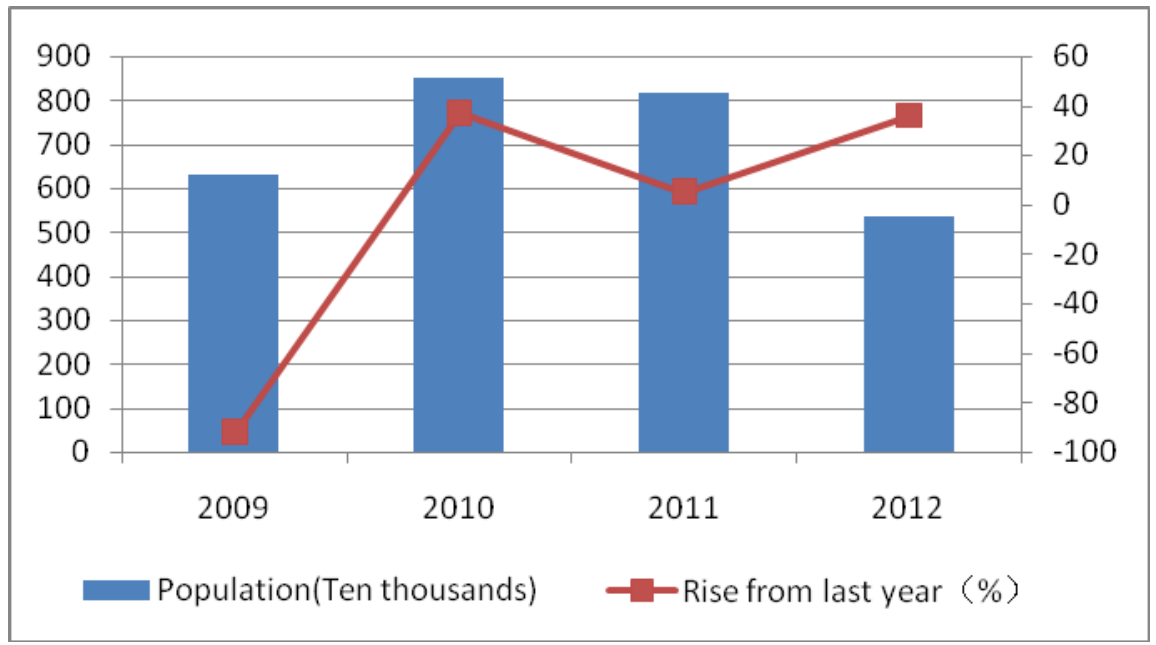

( Data source: Shanghai statistic network. http://www.stats-sh.gov.cn 。 International Inbound Tourists include: foreigners, Hongkong and Macao compatriots and Taiwan compatriots )

\section{Rise of major international conferences and foreign investment}

As the financial and trade center of China, frequent international business activities has attracted more and more overseas agency to settle down in shanghai. In view of an effective cost control, these companies tend to rent the serviced apartments because of the downtown location and good transportation with a price of only one third to the common hotels. Large amount of foreign managers 
and professionals pours into shanghai at the same time and they also like renting a place that can provide short-term residence with full range of facilities. Table 3 has shown sustaining increase in the number of foreign direct investment contracts since 2009. The figure is 816 more compared with 2009 in 2010, and 423 more in 2011 than in 2010. The first 8 months of 2012 has witnessed an increase of 442 compared with the 1987 contacts in 2009 in the corresponding period, and 12 more than the 2417 contacts in 2010 in the same period, 155 more than the 2274 contacts in 2011 regarding the same period.

Table 3 Foreign direct investment contracts number Unit $^{7}$

\begin{tabular}{|c|c|c|c|c|}
\hline Month & 2009 & 2010 & 2011 & 2012 \\
\hline 1 & 269 & 295 & 322 & 310 \\
\hline 2 & 263 & 216 & 217 & 175 \\
\hline 3 & 200 & 245 & 230 & 203 \\
\hline 4 & 238 & 322 & 277 & 361 \\
\hline 5 & 256 & 277 & 394 & 362 \\
\hline 6 & 242 & 332 & 391 & 360 \\
\hline 7 & 206 & 417 & 261 & 388 \\
\hline 8 & 313 & 313 & 382 & - \\
\hline 9 & 282 & 295 & 272 & - \\
\hline 10 & 231 & 342 & 520 & - \\
\hline 11 & 225 & 455 & 461 & 2429 \\
\hline 12 & 365 & 397 & 602 & 303.625 \\
\hline
\end{tabular}

(Data source: Shanghai statistic network http://www.stats-sh.gov.cn. Foreign direct investment is absorbed from Sino-foreign joint venture, Sino-foreign cooperative business, wholly foreign-owned enterprises and joint-equity enterprises. Foreign direct investment contracted project is also named Approved Project, which includes approved foreign investment enterprises and contractual projects among foreign direct investment. )

\section{Threat Analysis for Shanghai Serviced Apartment}

The rising price of serviced apartment is the major threat. Table 4 shows that the data fluctuated, but in general, rise was more than that of drop. Average change rate between 2003 and sep. 2012 shows 3 type of rent variation: 1 . overall rent presented a slide and the range is significant, for example Somerset Grand; 2. the price rose and fell all the time, but uptrend was greater than downtrend; 3. the overall rise of price and the range was great, such as Shanghai Center. General speaking, overall price level appears a rising trend.

Table 4 Monthly rent lists for part of Shanghai serviced apartments in 2003 and 2012 (yuan) ${ }^{2}$

\begin{tabular}{|c|c|c|c|c|}
\hline Estate & 2003 & 2012 & Range ability & Annual change rate \\
\hline New Harbour & $11587-24000$ & $14000-22000$ & $2413--2000$ & $2.31--0.92$ \\
\hline Arcadia Serviced Apartments & $19864-20692$ & $18000-30000$ & $-1864-9308$ & $-1.04-5.03$ \\
\hline Ascott Shanghai Pudong & $13243-52451$ & $25000-55000$ & $11757-2549$ & $9.87-0.54$ \\
\hline Tianci Service Apartment & $4135-14059$ & $12000-16000$ & $7865-1941$ & $21.1-15.3$ \\
\hline Somerset Grand Shanghai & $24810-82770$ & $17000-28000$ & $-7810-54770$ & $-3.5--7.35$ \\
\hline Grand Gateway Garden & $12405-20675$ & $17000-24000$ & $4595-3325$ & $4.1-1.79$ \\
\hline Shanghai Centre & $22347-46351$ & $45000-74000$ & $22653-27649$ & $11.27-6.63$ \\
\hline Jinqiao International Garden & $8277-13243$ & 14340 & $6063-1097$ & $8.14-0.92$ \\
\hline
\end{tabular}

(Data source: In table, negative sign means decrease, positive sign means increase. The results were converted with U.S dollor against Renminbi 8.277. Data of year 2007 was collected from Cityhome365.com.)

\section{Conclusions}


With the development of China's economy, Shanghai 12th five year plan points out that, Shanghai is accelerating its speed in building Four Center. Serviced apartment will face unprecedented opportunities of development. As its service quality getting enhanced, friends coming to Shanghai from all over the world can choose serviced apartment as their business, tourism, and relaxation place.

\section{References}

[1] Liang Bao'er, Zhu Chengqiang: A Study of Current Status of the Development of Shanghai's Hotel-Style-Serviced Apartments, Tourism Tribune,No.19, 2004-05, P66 71.

[2] Liu Houliang, Zhu Yaowu: Hotel-Style-Serviced Apartment Development Plight and Countermeasures-Take Development Situation of Shanghai Hotel-Style-Serviced Apartment as Modern Property Management, Urban Real Estate Industry, 2004-01, P36 38.

[3] Ye Ting, Study of Development Strategy of Nanjing’s Hotel-Style-Serviced Apartment Based on SWOT Analysis, Economic Research Guide, 2010-30, P148-149.

[4] Shi Yang: Shanghai's Hotel-Style-Serviced Apartments: Bright Market and Investment prospects, China Real Estate Information, 2005:P56.

[5] Zhang Ruoyang: Some Considerations for prospect of China's Hotel-Style-Serviced Apartment. Market Modernization, 2008-530:P203.

[6] Qunar? http://www.qunar.com

[7] Shanghai Statistic Network http://www.stats-sh.gov.cn

[8] Cityhome http://www.cityhome365.com

[9] Shanghai Municipal Government http://www.shanghai.gov.cn

[10] Real-estate websitehttp://www.house.china.com.cn/shanghai 